\title{
Conservation breeding programs and refined taxonomy as a political tool for biodiversity conservation: the de Beaux and Durrell legacies
}

\section{Spartaco Gippoliti}

Società Italiana per la Storia della Fauna "G. Altobello”; Viale Liegi 48, 00198 Roma, Italy Corresponding author $\bowtie$ : spartacolobus@hotmail.com

Received: 16 May 2019 Accepted: 22 August 2019

Published online: 30 September 2019

\begin{abstract}
Over the past decades, zoos and aquaria have shifted from an emphasis on ex situ conservation of animal species to strategies that emphasize educative and fund-raising efforts to halt environmental degradation 'in situ'. However, it is here proposed that 'ex situ' breeding programs have a strong educative potential and if they are coupled with a fine-grain taxonomy based on phylogenetic thinking, they can be perceived as a strong ethical message against homogenization of global biodiversity to be directed at global, national and local levels.
\end{abstract}

Key words: Zoos, phylogenetic systematics, local populations, evolutionary history, 'ex situ' conservation, endemism, tourism

\section{Introduction}

Traditionally, government authorities and some environmental organizations have considered ex situ conservation strategies with suspicion, one of the main reasons being that it may divert attention (and resources) from in situ conservation activities (Dolman et al., 2015). This view was probably influenced by the great charisma of some of the species involved, notably the critically endangered California Condor, Gymnogyps californianus (Shaw) (Snyder et al., 1996). Another reason is that zoo breeding programs are sometimes presented by naive stakeholders as an actual deliberate alternative to in situ conservation, a fact with which no serious conservation biologist can agree, as ex situ activities can be seen as an emergency phase while a more long-term solution is found (Redford et al., 2012). For example, this misunderstanding occurred with the Val-d'Or woodland caribou in Canada - an intrasubspecific conservation unit of Rangifer tarandus caribou Gmelin according to the prevailing outdated taxonomy (Geist, 2007) - only found in Quebec's Abitibi-Témiscamingue, when in 2016, a government proposal was made to put all the surviving individuals in a zoo because of the high costs of attempting to save them in situ (Page, 2018).

\section{Potentialities of ex situ conservation}

The present ex situ emphasis by the zoo community actually seems to overlook some of the political implications associated with the development of breeding programs in a zoo or in $a d$ hoc breeding facilities. Further, although the space available in zoos and similar facilities is not unlimited, it seems that there is ample space for allocating more space and resources to 
threatened taxa without significant extra cost (Marešová and Frynta, 2008; Gippoliti, 2012). As an example, several hundred brown bear individuals, Ursus arctos Linnaeus, of unknown origin are probably kept in European zoos but part of this occupied space could easily be made available to some of the most notable and threatened subspecies; such as Ursus arctos syriacus Hemprich and Ehrenberg, U. a. isabellinus Horsfield, U. a. pruinosus Blyth and $U$. a. marsicanus Altobello without incurring much extra cost.

Discussions over the conservation value of zoos have concentrated on the feasibility and success of reintroductions of captive-bred individuals to the wild (Conde et al., 2011; Gilbert et al., 2017). It is stressed here that conservation breeding programs (CBPs) have a crucial role in shaping conservation priorities and direct attention and resources toward the conservation of particular taxa, with positive feedback for the local biodiversity. It is true that sometimes captive breeding or translocations are presented as a easy way to overcome a problem - an endangered species - that block 'development' of a region, but this is usually done by governments in countries where the mission of zoos and 'ex situ' conservation is not fully understood.

Furthermore, CBP success is not simply the result of public exhibition, but rather a more complex and elaborate process that includes research activities and data collecting, scientific publications, educational tools and communications to a wider audience, including the scientific community and governments. Although private aviculturists can have a greater breeding success than zoos with several bird groups, they rarely can accomplish the other communicative goals of CBPs such as zoos or other international organizations like the Peregrine Fund (Jones et al., 1994). In such cases, CBPs have transformed obscure species into flagship ones (Gippoliti, 2011).

Hence the reference to Durrell's legacy seems fully justified as Gerald Durrell (1925-1995) and the zoo he founded in Jersey were pioneers in working on little-known insular endemic species (even smaller vertebrates such as frogs and geckos). These often became internationally-recognized flagship species, such as the Mauritius pink pigeon, Nesoenas mayeri (Prévost), due to the famous Jersey-based conservation program (Mallinson, 1991). But examples are not limited to island endemic species, nor to Durrell's work. The Kenyan bongo, Tragelaphus eurycerus isaaci (Thomas) shows remarkably well that a captive population can furnish not only demographic and genetic help to a dwindling wild population, but also offer a much needed 'voice' to a national conservation crisis (Reillo, 2002). Interestingly, a highly distinctive and equally threatened bongo, Tragelaphus eurycerus eurycerus (Ogilby) - possibly a distinct species - in the forested areas of the Guinean coast of West Africa (distributed from Sierra Leone to Benin) has received practically no attention by the conservation and zoo community (Gippoliti et al., 2018). Again, the conservation of the pygmy hog, Porcula salvania Hodgson in India is mostly due to the efforts of Durrell's zoo, and William Oliver specifically, even if the species is practically absent from any zoos outside India. Hence, it may seem that captive breeding and the zoo world may as well have a crucial role in biodiversity conservation, partly re-balancing well-known biases of allocation of conservation resources towards certain species and regions (Brockington and Scholfield, 2010).

The often, not fully disclosed, message of ex situ programs is one of an organism providing value to people who may have no specific cultural bond with the species, but who feel that there is an ethical duty to preserve biodiversity around the globe. This can be a powerful message to national governments and communities were these species live! In 1923, the International Society for the Protection of European Bison (formed in 1922 after the end of the First World War) had an active Italian Section even though the species had disappeared for millennia from Italy and no captive individuals were present there at the time. The 
Society's chair, the Italian zoologist Oscar de Beaux (1879-1956), author of a booklet entitled "Biological Ethics" (de Beaux, 1932), thought that the European bison, Bison bonasus (Linnaeus) was part of the heritage of all Europeans. Today in a fully globalised planet, we must try to council environmental globalism with respect for cultural localisms. Yet, in some circumstances, unilateral decisions to begin a conservation breeding program may increase awareness and offer a second chance to both the international community and more local communities.

\section{The relevance of taxonomy and phylogenetic systematics}

Increased awareness of local conservation priorities is certainly encouraged by a greater taxonomic knowledge of the world's biodiversity. Recognition of narrow endemics (at the subspecies or species level according to available evidence and the scientific philosophy adopted) is the first step to allow the flourishing of several local initiatives that the international community should try to encourage and support. For a series of conceptual and conservation-related problems linked to the subspecies category inside the Biological Species Concept (BSC), an alpha taxonomy based on a Phylogenetic Species Concept (PSC) is regarded by some conservationists as more scientifically sound (cf. Groves et al., 2017).

If we want prevent acts, such as the almost total extinction of the Nile or Northern white rhinoceros, Ceratotherium cottoni (Lydekker), we should stop lamenting civil unrest, poaching or guerilla warfare as unforeseeable events and begin to implement strong conservation initiatives and, among them, conservation breeding if feasible. Two cases linked to my recent scientific activities are of relevance here. In a recent paper (Gippoliti, 2017) I resurrected an old name, long fallen in synonymy, for a distinct species of patas monkey restricted to the Blue Nile region of Sudan and Ethiopia, Erythrocebus poliophaeus Reichenbach or Heuglin's patas monkey. Quite stunning photographs of patas monkeys living in zoos around the globe show that there are a few breeding groups of this species already in captivity in zoos in Egypt, China, and the Arabian Peninsula, but all so far subsumed under Erythrocebus patas (Schreber). In such cases, the establishment of an international breeding program in zoos is clearly warranted and should be fundamental to fostering biological research on the new species and attract interest towards an overlooked region of Africa. Actually, even if the Heuglin's patas monkey is not on the brink of extinction, conservation attention may benefit protected areas that have threatened or unique populations of other species, such as the Dinder NP in Sudan and the Alatash NP in Ethiopia (cf. Bauer et al., 2018).

In a quite different context, I was among the supporters for ex situ activities for the Apennine brown bear, Ursus arctos marsicanus in Italy (Guacci et al., 2013; Gippoliti, 2016). The Apennine brown bear is a very distinctive subspecies of brown bear (Meloro et al., 2017) whose population doesn't exceed 50 individuals, including only 13 breeding females, yet it shows a clearly distinct genome from other European brown bears (Benazzo et al., 2017). Although their breeding rate is normal, no population growth has been observed in recent years (Gervasi and Ciucci, 2018). This led to our proposal to begin collecting sperm and tissues for a genetic bank on one hand, while also asking to begin discussion about a traditional CBP. Many of these captive bears are in captivity as a result of being rescued as orphan cubs or as problematic individuals foraging inside human settlements. While the ex situ proposal was probably perceived as a criticism of the national protection system (particularly toward the Abruzzo Lazio and Molise National Parks that have protected this population since 1922), international bodies consulted about the issue replied that effectively the population is below long-term viability and, if there is no increase, the more feasible solution is restocking with nearby populations from the Balkans (Gippoliti and Guacci, 2017). Although no practical step (in either direction) has been taken at this time, I think that the appeal for ex situ conservation has achieved some important results, which I list below: 
1) Even if populations remain stable, there is a long-term danger to lose genetic variability and this apparently had never been recognized previously by Italian conservation bodies.

2) There is ambiguity at the international level regarding the taxonomic status of Ursus arctos marsicanus and what it means for conservation policy. This is a well-known scientific problem of the subspecies rank and conservation policies (Groves et al., 2017; Gippoliti, 2019) but there was apparently no awareness at the national level.

3) This small and unique bear population regained public relevance nationally after two decades of major attention had been previously directed toward the newly re-established Alpine population, certainly a conservation success, but not comparable in biological relevance with the endemic Apennine bear.

Therefore, zoo biologists can have a positive role even through provocative or unorthodox proposals such as that of fostering 'ex situ' plans in the core of Europe. Further, it seems that it is time for a critical revision of the harsh criticism of Phylogenetic Systematics and what has been defined as "taxonomic inflation" as originally employed by Meiri and Mace (2007). They argued against elevating subspecies to species rank as "Conservation funds are however limited, so this may in fact be achieved by diverting funds away from other species" (Meiri and Mace, 2007: 1385).

Biodiversity conservation to be successful should be endorsed by society and therefore is not simply a top-down process governed by a few centralized organizations. Support of iconic subspecies such as the mountain gorilla, Gorilla beringei beringei Matschie or the Asiatic lion, Panthera leo persica (Meyer) (or U. a. marsicanus in Italy) is mainly independent from the overall world budget assigned to the conservation of 'gorillas', 'lions' or 'brown bears'. Such distinctive taxa, whatever the taxonomic rank, are proudly national and/or local heritage and often a source of income for the local economy through nature-based, not mass-based, tourism. Taxonomic decisions should be independent from practical, economic or political considerations and should be based on the available evidence. Its aim is not to create stable species' lists for biologists and legislators but instead to map the evolutionary history of life in a more accurate way, treating species as refutable scientific hypotheses instead of fixed real entities (Groves et al., 2017; Raposo et al., 2017).

Finally, conservation biology is already involved with below-species diversity (Thakur et al., 2018) and the Sumatran tiger Panthera tigris sumatrae Pocock is the focus of in situ and ex situ programs irrespective if sumatrae denotes a species or a subspecies. The alarming decline of biodiversity, as measured by the loss of mammal and bird populations but not by IUCN status (Ceballos et al., 2017), indicates another possible positive outcome of utilizing a more fine-grained taxonomy based on the Phylogenetic Species Concept (PSC).

The great majority of 'subspecies' are, on the contrary, quite obscure to public opinion. Hence, the establishment of breeding programs for such distinctive taxa, as the Mexican and Florida wolf subspecies in the USA (Hedrick and Fredrickson, 2008) - incidentally now assigned to two distinct species, Canis lupus Linnaeus and Canis rufus Linnaeus (Chambers et al., 2012) - have a strong political message that has been overlooked so often: "we care for this "entity'!" This is in agreement with the ethical arguments of de Beaux (1930; 1932; see also Gippoliti, 2006) that believe we cannot dispose of living entities that we have not created. In his last paper (de Beaux, 1956); reviewing the genus Capra Linnaeus (ibexes, markhor and wild goats) he could not accept the taxonomy proposed by Ellerman and Morrison-Scott (1951) because of the excessive contractions and synonyms created by their over-synthesis of Capra diversity could not be useful for the conservation aim of the de Beaux paper. Otherwise, the risk exists that overlooking the relevance of distinctive lineages or subsets of a species may communicate that such entities are disposable and not of great biological 
relevance; thus potentially making weaker conservation policies and undermining community support. This could open the gate to a future where 'Anthropocene science' decides what to conserve and what not to conserve on the basis of purely subjective criteria (such as relevance, intelligence, beautiful appearance, phylogenetic closeness to humans, or economics). Although public preference is highly biased toward a few iconic large vertebrates, a better appreciation of the diversity of such iconic species or taxonomic groups through a PSC framework will allow a better distribution of conservation attention and resources. Recognition of the importance of two threatened chimpanzee taxa in West Africa, Pan troglodytes verus Schwarz and P. t. ellioti (Matschie) (Kormos et al., 2003), clearly offers indirect beneficial outcomes to the generally overlooked West African ecosystems.

Furthermore, the extinction of $U$. a. marsicanus or Acinonyx jubatus venaticus (Griffith) (Asiatic cheetah) - the latter also threatened by a short-minded translocation project of South African cheetah in India (cf. O’Brien et al., 2017) - may have far-reaching consequences for local communities that may look at quality, nature-based tourism as a possible sustainable alternative to exploitation of natural resources. Obviously, this is possible if travelling tourists may experience something unique and not just generalized 'brown bears' or 'cheetahs' that are much more easily visible elsewhere. Regarding zoo visitors, we may not expect a full appreciation of the importance of such narrow endemics (cf. Martin et al., 2014), yet there is ample space for innovative communication and 'storytelling' that fully exploit the potential of these taxa as flagship conservation species for their unique biodiversity hotspot.

\section{Conclusions}

Zoos and their staff have a great potential, if associated with Natural History experts and institutions, to contribute their work to slowing down biodiversity erosion and biotic homogenization around the Planet, as achieved by the Durrell's Trust (Young et al., 2014), but they need to explore new grounds for maintaining an emphasis on biodiversity issues. Specifically, it is suggested that with the aid of new technologies applied to communication, breeding programs may have a greater positive effect globally, and within the natural range of the target species, encouraging field conservation activities that benefit the target species and the whole ecosystem irrespective of the direct release of captive-bred individuals.

Although zoos cannot embrace every threatened species, they can carefully choose taxa that originate from overlooked regions or biodiversity hotspots, such as West African rainforests or Sunda Islands. Through appropriate exhibition and communication, zoos can make a difference in the future conservation of valuable taxa and ecosystems around the globe; even if they transform just a small percentage of their 700 million annual visitors into competent biophilia supporters.

\section{Conflict of Interest Statement}

The present work was carried out in the absence of any personal, professional or financial relationships that could potentially be construed as a conflict of interest.

\section{Acknowledgements}

The paper benefited from the criticism and suggestions of Corrado Battisti, William Conway, Jan Robovský, Indigo Taylor-Noguera, Roland Wirth and two anonymous referees, and to whom I express my deep gratitude. 


\section{References}

Bauer, H., Mohammed, A. A., El Faki, A., Hiwytalla, K. O., Bedin, E., Rskay, G., Sitotaw, E. and Sillero-Zubiri, C. (2018). Antelopes of the Dinder-Alatash transboundary Protected Area, Sudan and Ethiopia. Gnusletter, 35 (1): 26-30.

Benazzo, A., Trucchi, E., Cahill, J. A., Delser, P. M., Mona, S., Fumagalli, M., Bunnefeld, L., Cornetti, L., Ghirotto, S., Girardi, M., Ometto, L., Panziera, A., Rota-Stabelli, O., Zanetti, E., Karamanlidis, A., Groff, C., Paule, L., Gentile, L., Vilà, C., Vicario, S., Boitani, L., Orlando, L., Fuselli, S., Vernesi, C., Shapiro, B., Ciucci, P. and Bertorelle, G. (2017). Survival and divergence in a small group: The extraordinary genomic history of the endangered Apennine brown bear stragglers. Proceeding of the National Academy of Sciences of the United States of America, 114 (45): E9589-E9597. https://doi.org/10.1073/pnas.1707279114

Brockington, D. and Scholfield, K. (2010). Expenditure by conservation nongovernmental organizations in sub-Saharan Africa. Conservation Letters, 3 (2): 106-113. https://doi.org/10.1111/j.1755-263X.2010.00094.x

Ceballos, G., Ehrlich, P. R. and Dirzo, R. (2017). Biological annihilation via the ongoing sixth mass extinction signaled by vertebrate population losses and declines. Proceeding of the National Academy of Sciences of the United States of America, 114 (30): E6089E6096. https://doi.org/10.1073/pnas.1704949114

Chambers, S. M., Fain, S. R., Fazio, B. and Amaral, M. (2012). An account of the taxonomy of North American wolves from morphological and genetic analyses. North American Fauna, 77: 1-67. https://doi.org/10.3996/nafa.77.0001

Conde, D. A., Flesness, N., Colchero, F., Jones, O. R. and Scheuerlein, A. (2011). An emerging role of zoos to conserve biodiversity. Science, 331 (6023): 1390-1391. https://doi.org/10.1126/science.1200674

de Beaux, O. (1930). Etica Biologica. Tentativo di risveglio di una coscienza naturalistica. Temi, Trento. [in Italian]

de Beaux, O. (1932). Biological Ethics. An attempt to arouse a naturalistic conscience. The Italian Mail and Tribune, Firenze.

de Beaux, O. (1956). Posizione sistematica degli stambecchi e capre selvatiche viventi (Capra Linneo 1758) e loro distribuzione geografica. Atti Accademia Scienze e Lettere Genova, 12: $123-228$.

Dolman, P. M., Collar, N. J., Scotland, K. M. and Burnside, R. J. (2015). Ark or park: the need to predict relative effectiveness of ex situ and in situ conservation before attempting captive breeding. Journal of Applied Ecology, 52 (4): 841-850. https://doi.org/10.1111/ 1365-2664.12449

Ellerman, J. R. and Morrison-Scott, T. C. S. (1951). Second edition. Checklist of Palaearctic and Indian mammals 1758 to 1946. British Museum (Natural History), London.

Geist, V. (2007). Defining subspecies, invalid taxonomic tools, and the fate of the woodland caribou. Rangifer, 27 (4): 25-28. https://doi.org/10.7557/2.27.4.315

Gervasi, V. and Ciucci, P. (2018). Demographic projections of the Apennine brown bear population Ursus arctos marsicanus (Mammalia: Ursidae) under alternative management scenarios. The European Zoological Journal, 85 (1): 242-252. https://doi.org/10.1080/24750263.2018.1478003

Gilbert, T., Gardner, R., Kraaijeveld, A. R. and Riordan, P. (2017). Contributions of zoos and aquariums to reintroductions: historical reintroduction efforts in the context of changing 
conservation perspectives. International Zoo Yearbook, 51 (1): 15-31. https://doi.org /10.1111/izy. 12159

Gippoliti, S. (2006). Oscar de Beaux: a noteworthy Italian mammalogist and conservationist. Italian Journal of Zoology, 73 (3): 285-289. https://doi.org/10.1080/112 500006008 21361

Gippoliti, S. (2011). Zoos and conservation in the XXI Century: Overlooked meeting points between ecology and social sciences? Museologia Scientifica, 5 (1-2): 168-176.

Gippoliti, S. (2012). Ex situ conservation programmes in European Zoological Gardens: Can we afford to lose them? Biodiversity and Conservation, 21 (6): 1359-1364. https://doi.org/10.1007/s10531-012-0256-8

Gippoliti, S. (2016). Questioning current practice in brown bear, Ursus arctos, conservation in Europe that undervalues taxonomy. Animal Biodiversity and Conservation, 39.2: 199205. https://doi.org/10.32800/abc.2016.39.0199

Gippoliti, S. (2017). On the taxonomy of Erythrocebus with a re-evaluation of Erythrocebus poliophaeus (Reichenbach, 1862) from the Blue Nile Region of Sudan and Ethiopia. Primate Conservation, 31: 53-59.

Gippoliti, S. (2019). Species delimitation in mammals: A comment on Zachos (2018). Mammalian Biology, 94: 127-131. https://doi.org/10.1016/j.mambio.2018.05.007

Gippoliti, S. and Guacci, C. (2017). Il mammifero italiano più minacciato: l'Orso marsicano. Un approccio interdisciplinare per la sua conservazione. Natura e Montagna, 64 (2-3): 29-35. [in Italian]

Gippoliti, S., Lupták, P. and Groves, C. P. (2018). Flagship but only locally: bongo Tragelaphus eurycerus taxonomic history and its effects on current conservation policy. Gazella (Praha), 44: 65-77.

Groves, C. P., Cotterill, F. P. D., Gippoliti, S., Robovský, J., Roos, C., Taylor, P. J. and Zinner, D. (2017). Species definitions and conservation: a review and case studies from African mammals. Conservation Genetics, 18 (6): 1247-1256. https://doi.org/10.1007/ s10592-017-0976-0

Guacci, C., Ferri, M. and Gippoliti, S. (2013). Un manifesto pro conservazione "ex situ" dell'orso bruno marsicano Ursus arctos marsicanus Altobello, 1921. Biologia Ambientale, 27 (2): 55-58. [In Italian]

Hedrick, P. W. and Fredrickson, R. J. (2008). Captive breeding and the reintroduction of Mexican and red wolves. Molecular Ecology, 17 (1): 344-350. https://doi.org/10.1111/j. 1365-294X.2007.03400.x

Jones, C. G., Heck, W., Lewis, R. E., Mungroo, Y., Slade, G. and Cade, T. (1994). The restoration of the Mauritius kestrel Falco punctatus population. Ibis, 137 (1): 173-180. https://doi.org/10.1111/j.1474-919X.1995.tb08439.x

Kormos, R., Boesch, C., Bakarr, M. I., and Butynski, T. M. (2003). West African chimpanzees: Status survey and conservation action plan. IUCN/SSC Primate Specialist Group, IUCN, Gland, Switzerland and Cambridge, UK. ix + 219 pp.

Mallinson, J. J. C. (1991). Partnerships for conservation between zoos, local governments and non-governmental organizations. Symposia of the Zoological Society of London, 62: 5774.

Marešová, J. and Frynta, D. (2008). Noah's Ark is full of common species attractive to humans: the case of boid snakes in zoos. Ecological Economics, 64 (3): 554-558. https://doi.org/10.1016/j.ecolecon.2007.03.012 
Martin, T. E., Lurbiecki, H., Joy, J. B. and Mooers, A. O. (2014). Mammal and bird species held in zoos are less endemic and less threatened than their close relatives not held in zoos. Animal Conservation, 17 (2): 89-96. https://doi.org/10.1111/acv.12069

Meiri, S. and Mace, G. M. (2007). New taxonomy and the origin of species. PLOS Biology, 5 (7): e194. https://doi.org/10.1371/journal.pbio.0050194

Meloro, C., Guidarelli, G., Colangelo, P., Ciucci, P. and Loy, A. (2017). Mandible size and shape in extant Ursidae (Carnivora, Mammalia): A tool for taxonomy and ecogeography. Journal of Zoological Systematics and Evolutionary Research, 55 (4): 269-287. https://doi.org/10.1111/jzs.12171

O'Brien, S. J., Johnson, W. E., Driscoll, C. A., Dobrynin, P. and Marker, L. (2017). Conservation genetics of the cheetah: Lessons learned and new opportunities. Journal of Heredity, 108 (6): 671-677. https://doi.org/10.1093/jhered/esx047

Page, J. (2018). Efforts to save woodland caribou in northern Quebec too costly, says province. CBC News, 9 March 2018.

Raposo, M. A., Stopiglia, R., Brito, G. R. R., Bockmann, F. A., Kirwan, G. M., Gayon, J. and Dubois, A. (2017). What really hampers taxonomy and conservation? A riposte to Garnett and Christidis. Zootaxa, 4317 (1): 179-184. https://doi.org/10.11646/zootaxa .4317 .1 .10

Redford, K. H., Jensen, D. B. and Breheny, J. J. (2012). Integrating the captive and the wild. Science, 338 (6111): 1157-1158. https://doi.org/10.1126/science.1228899

Reillo, P. (2002). Repatriation of mountain bongo to Kenya. Gnusletter, 21 (2): 11-15.

Snyder, N. F. R., Derrickson, S. C., Beissinger, S. R., Wiley, J. W., Smith, T. B., Toone, W. D. and Miller, B. (1996). Limitations of captive breeding in endangered species recovery. Conservation Biology, 10 (2): 338-348. https://doi.org/10.1046/j.1523-1739.1996. 10020338.x

Thakur, M., Wullschleger Schättin, E. and McShea, W. J. (2018). Globally common, locally rare: revisiting disregarded genetic diversity for conservation planning of widespread species. Biodiversity and Conservation, 27 (11): 3031-3035. https://doi.org/10.1007/s10531-018-1579-X

Young, R. P., Hudson, M. A., Terry, A. M. R., Jones, C. G., Lewis, R. E., Tatayah, V., Zuël, N. and Butchart, S. H. M. (2014). Accounting for conservation: Using the IUCN Red List Index to evaluate the impact of a conservation organization. Biological Conservation, 180: 84-96. https://doi.org/10.1016/j.biocon.2014.09.039 